\title{
UNA VOZ FEMENINA EN EL TEATRO DE MEDIADOS DEL XIX: LA COMEDIA DE GERTRUDIS GÓMEZ DE AVELLANEDA
}

\author{
Rosalía FERNÁNDEZ CABEZÓN \\ Universidad de Valladolid
}

\section{RESUMEN}

El análisis de siete comedias de Gertrudis Gómez de Avellaneda nos descubre la voz de una dramaturga valiente, inconformista, que expone sus ideas en torno a una serie de problemas que le preocupan, así se manifiesta a favor del amor sin presiones familiares, económicas o sociales, donde se pueda elegir con libertad al cónyuge, rechazando los matrimonios concertados porque sólo traen la infelicidad de los contrayentes. Respecto al papel de la mujer en la sociedad de su tiempo, censura la total dependencia de éstas respecto a los varones y critica cómo están sometidas a unos estrictos códigos de conducta que ellos les imponen, adelantándose en muchos años a las denuncias feministas.

Palabras clave: Comedia decimonónica, Gertrudis Gómez de Avellaneda, propuestas feministas.

\begin{abstract}
The analysis of seven comedies by Gertrudis Gómez de Avellaneda discovers a courageous, nonconformist female playwright who voices her ideas on a series of problems that worried her. She champions love when one's spouse may be chosen at will, unhampered by family, economic and social pressure, thus rejecting arranged marriages which bring nothing but misery to both parties. With regard to the role of women in her day, she censures their total dependence on men; her criticism of the strict codes of conduct imposed on women prefigure the feminist denunciations which will only come many years later.
\end{abstract}

Key words: 19 th-century comedy, Gertrudis Gómez de Avellaneda, feminist proposals.

Anales, 23, 2011, pp. 309-321 
La cubana Gertrudis Gómez de Avellaneda (1814-1873), además de una estimable poetisa y novelista, destaca por ser una de las dramaturgas más aplaudidas del siglo XIX español (Gies, 1996: 271-285). Cultivó con éxito los más variados géneros teatrales: tragedia, drama, comedia, que hacen de ella un típico ejemplo del hibridismo que singulariza la época (Rubio Jiménez, 1988: 643).

Después de sus grandes estrenos en la década de los cuarenta (Munio Alfonso, El príncipe de Viana, Egilona, Saúl...) donde la autora se decanta por una modalidad mixta (ecléctica) en la que se fusionan elementos de la tragedia con los del drama romántico (Villaverde, 1981: 200-209), a partir de los años cincuenta - a excepción de Recaredo (1851), La verdad vence apariencias (1852) y Baltasar (1858) - su producción dramática se inclina hacia la comedia, género en el que la Avellaneda proyecta su rica y compleja personalidad, especialmente en algunos de los temas que más le preocupan como son el amor, el matrimonio, el papel de la mujer en la sociedad de su tiempo...

En las piezas recogidas (Errores del corazón (1852), La hija de las flores (1852), La Aventurera (1853), Simpatía y antipatía (1855), Oráculos de Talía (1855), Tres amores (1858) y El millonario y la maleta (1870), las relaciones amorosas de sus protagonistas presentan una variada casuística.

En Errores del corazón, tildada de sentimental por la crítica (Cotarelo, 1929: 406), el doctor Román, un médico filántropo, ama apasionadamente a una paciente a la que ha salvado la vida, la condesa de Valsano. En la escena $\mathrm{V}$ del acto inicial, en diálogo con su protegida María, expresa la intensidad de ese sentimiento que le embarga en términos que recuerdan los que la propia Gertrudis emplea en sus Cartas a Ignacio Cepeda (Cruz de Fuentes, 1914: 87-144):

... yo hablo de aquel sentimiento vivo, absoluto... de aquel amor que hace de un ser todo el universo para el corazón que lo abriga [...] que llena el alma sin dejar espacio para ninguna otra pasión..., de aquel amor que no consiente límites, que necesita la posesión completa exclusiva del objeto amado... de aquel amor de deseos infinitos, ¡de aspiraciones eternas! (Gómez de Avellaneda, 1977: 53).

Por su parte María, a pesar de la diferencia de edad que les separa, ella tiene 19 años y el doctor 45, está enamorada en secreto de su protector, y recrimina la poca fortaleza que éste demuestra cuando la condesa le confiesa que ama a Fernando, un pariente del médico. Por boca de María, la dramaturga - que hasta esa fecha ha estado enamorada primero de Cepeda, en Sevilla, y posteriormente de Gabriel García Tassara, en Madrid, sin lograr ser correspondida como ella hubiera deseado (Bravo Villasante, 1986: 41-52 y 80-88)- defiende con vehemencia la superior capacidad que poseen las mujeres para el sufrimiento frente a la actitud de los hombres: 
¡El alma que sabe amar no ha de sufrirlo todo! ¡Ellos, los seres que se llaman fuertes, carecen acaso de este gran poder del sufrimiento que yo encuentro en mi alma! ¿Seremos nosotras, las criaturas débiles, las que poseemos únicamente el valor supremo de la resignación? (Gómez de Avellaneda, 1977: 77-78)

La joven, preocupada por la salud del doctor, que sólo recuperará si consigue el amor de la condesa, no duda en sacrificarse; para ello debe desvelar a la noble que el médico tiene destrozado el alma porque «jama y no es amado!» (81); le ruega que en un esfuerzo supremo acepte ser su esposa, pero la condesa no es capaz de desmentir a su corazón. El doctor, a fin de aliviar su pena, decide refugiarse en la soledad del campo, pero María no está dispuesta a separarse de él y entre delirios le confiesa su amor, lo que provocará los remordimientos del médico, que se siente al mismo tiempo «víctima y verdugo» (91).

Muy diversa es la postura de Fernando en sus relaciones con el sexo femenino. Durante la enfermedad de la condesa ha cortejado a la hermana de ésta por ser la heredera de «una dote de las mejores de España» (48); aclara sin arrobo que debido a su escaso patrimonio tiene que contraer «un casamiento por razón de Estado» (49), por ello juzga conveniente corresponder a la rica condesa, lo que motiva la indignación del doctor quien lo acusa de no tener corazón, de dejarse llevar por el positivismo material que caracteriza a la época, donde la sed de oro es lo único que preocupa a los jóvenes. Cuando la condesa descubre el galanteo que Fernando mantuvo con su hermana rompe el compromiso decidida a dar su mano al doctor, pero éste la rechaza y elige como esposa «a la mujer angelical a quien venera mi alma» (123), es decir, a María.

De corte sentimental (Gómez de Avellaneda, 1977: 15) es también la comedia Tres amores, que la autora ambienta en el reinado de Carlos III. En un pueblecito de la montaña navarra, Antonio, un labrador, está enamorado de Matilde, una joven que ha sido criada por la familia de él y de quien se desconocen sus padres. El labrador cifra su existencia en hacer feliz a Matilde, con quien desea casarse. Sin embargo, la llegada de un poeta, Víctor San Adrián, perturba esa relación juvenil porque Matilde se siente atraída por los versos y por el lenguaje apasionado de San Adrián y así confiesa a la criada que se ha operado en ella un cambio en su existencia:

No puedo negar ni explicar lo que me inspira. Sus miradas me fascinan, sus palabras me abren un mundo nuevo, que me atrae con el poderoso encanto de lo desconocido... (Gómez de Avellaneda, 1981: 138) 
Unas cartas que recibe San Adrián en las que su pariente, el conde de Lárraga, le destina a su única hija como esposa (necesita un gran casamiento porque no dispone de fortuna) y el nombramiento para un cargo diplomático precipitan la marcha del poeta y la desventura de Matilde, porque cuando ésta le desvela que le ama y que está dispuesta a convertirse en su esposa, él la rechaza en estos términos:»No veo en usted la mujer de mi porvenir... de mis aspiraciones...» (140)

En el personaje de San Adrián algunos críticos han querido ver una posible alusión a Gabriel García Tassara, poeta con el cual la Avellaneda había mantenido en el pasado unas tormentosas relaciones amorosas y que había abandonado su profesión de escritor aceptando un cargo en la carrera diplomática (Cotarelo, 1929: 571).

Pero Matilde no se resigna a quedarse sepultada entre esos montes, desea alcanzar la gloria, es la única forma que tiene para superar la distancia que la separa de San Adrián, para hallarse a su altura:

¡Yo necesito llegar hasta él! ¡Lo necesito, y me siento con fuerzas para alcanzarlo! Él se ha ceñido la corona del genio... ¡Pues bien!... ¡Yo también quiero esa corona!... (141)

Por ello, cuando tiene noticia de que sus familiares sin consultarla (tiranos, les denomina) la destinan a un convento, decide huir acompañada por Antonio, quien generosamente pone a su disposición la herencia de su tío porque le dice: «tú eres para mí más que el universo» (141).

Cinco años después, bajo el nombre de Celia, Matilde convertida en actriz está a punto de protagonizar en Madrid la tragedia de San Adrián titulada Safo, regalada por el abnegado Antonio que en calidad de hermano ha procurado la instrucción de su amada sin escatimar gastos en maestros y libros, e incluso se ha puesto a trabajar como ebanista a fin de que sus fondos no disminuyan gravemente. El encuentro entre la actriz y el poeta reaviva el antiguo sentimiento de la joven y tras el éxito en las tablas Matilde le confiesa jubilosa que por fin ha alcanzado la gloria a que aspiraba, por fin ha llegado a su altura y está dispuesta a sacrificarse, dejando la escena, si él la ama, si pueden compartir sus vidas. Sin embargo, San Adrián - a quien su parienta Leonor ha definido como de «vasta inteligencia, pero de corazón árido, ambicioso...» (148), no quiere comprometerse con los lazos del matrimonio, todavía les separa la distancia del nacimiento, y por ello alega en su rechazo:

... hay en el mundo convenciones que es menester respetar... deberes sociales de los que no prescinden jamás hombres de mi clase. Sabes que pertenezco a la ilustre familia... (155) 
No obstante, esa supuesta distancia social no es tal porque Matilde es hija de Leonor, única hermana del conde de Lárraga, en quien éste, después de la muerte de su hija, quiere hacer recaer sus títulos y su fortuna, arrepentido porque en el pasado había impedido la felicidad de su hermana, al oponerse por orgullo y "por no deslustrar sus timbres» (148) al matrimonio de ésta con un artista de talento, aunque ella se casará secretamente, de cuya unión nacerá Matilde; en este sentido, la dramaturga levanta su voz contra las rígidas leyes vigentes en la España del setecientos, periodo en el que se desarrolla la acción, donde los jóvenes menores de veinticinco años están obligados por la Pragmática de Carlos III de 23 de marzo de 1776:

... para celebrar el contrato de esponsales, pedir y obtener el consejo y consentimiento de su padre, y en su defecto de la madre, y a falta de ambos, de los abuelos por ambas líneas respectivamente, y no teniéndolos, de los dos parientes más cercanos que se hallen en la mayor edad [...] Si llegase a celebrarse el matrimonio sin el referido consentimiento o consejo, por este mero hecho, así los que lo contraxesen, como los hijos y descendientes que provinieren del tal matrimonio, quedarán inhábiles, y privados de todos los efectos civiles, como son el derecho a pedir dote o legítimas, y de suceder como herederos forzosos y necesarios en los bienes libres, que pudieran corresponderles por herencia de sus padres o abuelos, a cuyo respeto y obediencia faltaron contra lo dispuesto en esta pragmática... ${ }^{1}$

El conde de Lárraga, a fin de reparar esa injusticia cometida hace veinticuatro años, reconocerá como válido y legítimo el casamiento de su hermana y declarará heredera y poseedora de todos sus títulos y riquezas a su sobrina Matilde, a quien destina como esposa de San Adrián, pero ella de forma sorprendente le rechaza formulando la teoría -la de la dramaturga- sobre la existencia de tres tipos de amores: el primero es el amor calculado, el de la vanidad y los sentidos, un amor que puede conciliarse con intereses bastardos y ruines, representado por Víctor San Adrián. El segundo es el amor de la cabeza, el del orgullo y del entusiasmo, que se lanza a la búsqueda de una aspiración soberbia, un amor iluso que prodiga tesoros al ídolo de culto. Ese es el que Matilde sentía por San Adrián. Por último, existe un tercer amor, el puro, el sublime, capaz de soportarlo todo, de los mayores sacrificios, ese es el amor de corazón que sólo atesoran las almas grandes como Antonio, y por ello es digno de que le conceda su mano, renunciando al título de condesa.

1. Novísima Recopilación de las Leyes de España, en Los códigos españoles concordados y anotados, Madrid, Imprenta de la Publicidad, a cargo de D. M. Rivadeneyra, 1850, Libro X, Título II, Ley IX, pp. 314-315. 
Al leer estas frases, cómo no traer a colación las palabras que Gertrudis escribe a Antonio Romero Ruiz, en la primavera de 1853, sincerándose sobre su antigua relación con Tassara:

Por mi parte sólo te diré que una sola vez he creído amar. El amor, tal cual yo lo concibo y lo he menester, no he hallado quien me lo inspire, ni quien lo sienta por mí. Pero abrigué largo tiempo un sentimiento enérgico, único de su especie que he sentido. No fui víctima de un abandono vulgar: mi desgracia consistió en que me dejé subyugar de las cualidades de la inteligencia sin cuidarme de las del corazón...(Bravo Villasante, 1986: 154-5)

El deseo de gloria, el valor del talento es, asimismo, el tema recurrente en la comedia Oráculos de Talía, pieza de enredo que ha sido puesta en relación con La dama duende de Calderón de la Barca (Cotarelo, 1929: 550). En ella el protagonista Fernando Valenzuela, un dramaturgo del siglo XVII, reivindica el noble empleo del autor dramático a pesar de las privaciones que tiene que sufrir, frente a la estabilidad económica y social que le puede proporcionar una carrera civil como defiende su criado Valentín:

Yo tengo fe, Valentín, en el genio, a quien fortuna

tributo debe rendir.

El talento es patrimonio. (Gómez de Avellaneda, 1979: 237)

Piensa que su valía ha sido por fin reconocida cuando varios nobles cortesanos le encargan una comedia para ser representada en el palacio real; su entusiasmo es tal que ingenuamente exclama:

$¡$ Oh no! no es la intriga sola,

ni el personal interés,

ni los bastardos manejos,

ni la lisonja soez

los que imperan en el mundo,

y en él consiguen sostén.

¡Aun hay justicia en el hombre!

¡Aun hay para el genio prez! (248)

Valenzuela, halagado por los supuestos protectores, cree que el talento se respeta y que su carrera como dramaturgo puede ser útil en el servicio de la patria. Sin embargo, pronto saldrá de su error; podrá comprobar con desilusión cómo los nobles lo único que pretenden es comprar su conciencia, cómo va a participar por amor a la ambiciosa Eugenia de Uceda en las intrigas cortesanas, descubriendo que sus mecenas tan sólo desean la caída de la reina Doña Mariana durante la minoría de Carlos II para entronizar a Don Juan José de Austria, el hijo de la Calderona. El protagonista que permanece fiel a 
la soberana es elevado a la categoría de ministro, pero no sin desmentir lo que antes había afirmado:

$$
\begin{aligned}
& \text {... no hay senda } \\
& \text { para el ingenio en España, } \\
& \text { si de su índole no abjura, } \\
& \text { si su entusiasmo no apaga, } \\
& \text { si con bajezas o intrigas } \\
& \text { favor bastardo no alcanza, } \\
& \text { o los públicos poderes } \\
& \text { con audaz empeño asalta. (311) }
\end{aligned}
$$

Versos llenos de amargura que reflejan el verdadero sentir de la Avellaneda, quien a pesar de ser una escritora de éxito (ha publicado poemas, varias novelas, estrenado dramas) ha visto cómo sus pretensiones de obtener algún cargo en la corte de Isabel II, primero en 1845 y después en 1851, no han recibido una respuesta favorable (Bravo Villasante, 1986: 126-7 y 135), y lo que para ella supuso un enorme disgusto, la negativa de ser aceptada en la Real Academia Española al estar vacante una plaza por muerte de su gran amigo Juan Nicasio Gallego en 1853. Aunque cuenta con influyentes valedores su candidatura fue rechazada «por la cuestión del sexo» (Bravo Villasante, 1986: 146-8).

Por esos mismos años, en 1856, se quejaba en carta a Leopoldo Augusto de Cueto del nulo reconocimiento oficial que había tenido:

Soy acaso el único escritor de España que jamás ha alcanzado de ningún gobierno distinción ni reconpenza (sic) grande o chica. Mi sexo ha sido eterno obstáculo a la buena voluntad que algunos ministros me han manifestado, y mi amor propio herido ha tenido, sin embargo, que aceptar como buenas las razones que, fundándose siempre en mi falta de barbas, se han servido elegir muchos hombres ilustrados para justificar la escepción (sic) poco grata que se ha hecho de mí. (Gómez de Avellaneda, 1974: 143)

Otro motivo que Gertrudis Gómez de Avellaneda aborda en algunas de sus comedias es el de los matrimonios concertados. Sabemos por su Autobiografía cómo desde que tenía quince años su familia tenía planeado casarla con un caballero de la isla. Ella -quizás por parecerle muy lejana la fecha de la boda- no se manifiesta en contra, pero cuando por fin el enlace es inminente no se halla «con fuerzas para consumar el sacrificio» y para evitarlo se fuga a casa de su abuelo, lo que produjo una gran consternación tanto en el ámbito doméstico como social «la opinión pública me condenaba», escribe al respecto (Cruz de Fuentes, 1914: 44-59).

La Avellaneda plantea este asunto con suma delicadeza en La hija de las flores, en la que Luis, un joven de 23 años, por respeto a su tío, debe casarse 
con Inés, una mujer de 36 años, aspecto que a juicio de Gies supone una inversión del patrón ofrecido en la comedia maestra de Leandro Fernández de Moratín, El sí de las niñas (Gies, 1996: 278), obra cuyo recuerdo de don Carlos pudo influir en la construcción del personaje de Luis (Mayoral, 1995: 150). Éste, aunque no ama a su prometida, ha aceptado esa unión para satisfacer las expectativas de su tío, pero llegado el momento decisivo siente una inmensa tristeza por la pérdida de libertad, si bien su tío le hace notar que nunca forzó su albedrío y que él dio su consentimiento. También la dama siente aversión por ese enlace, que la hace muy infeliz, hubiera preferido retirarse a la soledad del claustro, pero por obedecer a su padre ha aceptado el sacrificio.

La trama se complica cuando Luis conoce en la finca a Flora, una muchacha de origen desconocido, de quien se enamora apasionadamente. Flora en su ingenuidad cree que si le ama a ella no debe casarse con otra; es más, le propone con decisión que huyan a lejanas tierras donde nadie les mande, pero Luis, un galán respetuoso con las normas y con la palabra dada, rehuye su propuesta en estos significativos versos:

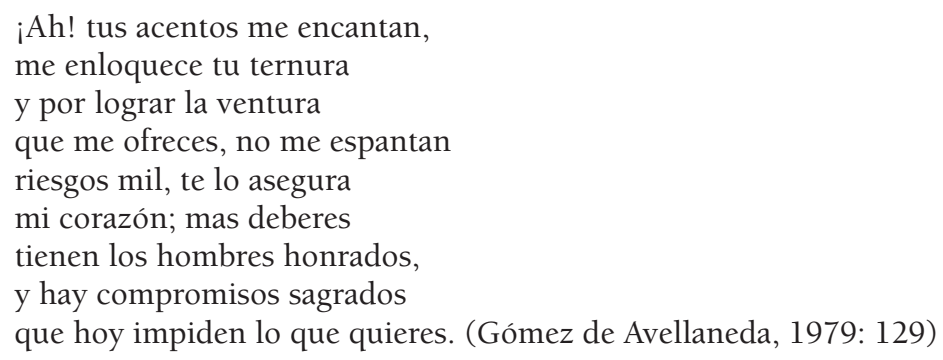

Determinadas actitudes de los prometidos hace pensar a éstos que el otro no tiene sano el juicio y de ser así el matrimonio podría evitarse. Al comprobar que los dos razonan con cordura cada uno sugiere que sea el otro quien rompa el compromiso; Luis le propone a Inés que sea ella quien rompa, pero la dama prefiere que sea él quien dé ese paso apoyándose en el tradicional papel pasivo de la mujer («Mi sexo es muy tímido», 133), en su innata sumisión para hacer recaer en el hombre el peso de la ruptura. Luis, sin embargo, alega que una señora de cierta edad no debe dejarse mandar en asuntos tan graves, debe escoger a gusto a su futuro marido (Mayoral, 1995: 147-8). En ambos casos, ninguno quiere contrariar la autoridad de su padre (Inés) o de su tío (Luis); el sentido de la obediencia filial pesa más que sus propios sentimientos.

Finalmente todo se resuelve cuando Inés confiesa la pena que le martiriza: violada en su juventud, tuvo una hija que cree muerta, pero el tío de Luis, que es el ofensor, le revela que Flora es el fruto de ese crimen, ofreciéndose a 
reparar su honor casándose con ella; asimismo, darán su aprobación para que se celebre el matrimonio, esta vez por amor, entre Luis y Flora.

De nuevo la dramaturga refleja en esta comedia dolorosas experiencias personales, como son la preocupación que demuestra por los hijos naturales y por la deshonra de la mujer, y que sin duda hay que poner en relación con la hija (María-Brenilde) que tuvo en 1845, fruto de sus amores con Tassara, a la que éste nunca reconoció, ni tan siquiera cuando la niña está en el lecho de muerte (Bravo-Villasante, 1986: 94-98).

El tema de los matrimonios concertados volverá a tratarlo en la pieza en un acto titulada Simpatía y antipatía. En ella Isabel anhela el divorcio porque está casada con un hombre del que le separa una profunda discordancia; en su confesión achaca a un destino aciago esa unión desgraciada:

Pues bien, si un hado maligno

por un capricho ligara

con vínculo santo, eterno,

a dos seres que se hallaran

por antipática fuerza

separados... (Gómez de Avellaneda, 1977: 375)

Esta dama no puede corresponder al amor que le profesa el conde porque es una mujer casada, temerosa de su honor, que debe respetar un compromiso sancionado por la Iglesia. Sabe que obtener la anulación en Roma es una misión difícil, pero como la decisión partió de su consorte, si lo consigue, si queda libre, ingresará en un convento.

Por su parte, el conde es también un hombre casado, que relata las circunstancias del enlace a pesar de su oposición. Desde pequeño vivía con un deudo de su madre, un anciano que era el tutor de una niña, quien sólo desea unir a estos jóvenes en matrimonio a fin de que su herencia no se divida y aún a sabiendas de que ambos tienen genios encontrados. Separados durante muchos años, los contrayentes no pueden contrariarle a la hora de su muerte y aceptan el himeneo, que se celebrará por poderes, aunque desde entonces todas sus gestiones han estado encaminadas a lograr el ansiado divorcio. Cuando a través de la narración los esposos se reconocen como cónyuges y comprueban cómo la antigua antipatía se ha convertido en un amor sincero, tratarán de paralizar el pleito que les conducía a la separación matrimonial.

No es ésta la primera vez que la Avellaneda expresa literariamente sus ideas en torno al controvertido asunto del divorcio. En su novela Dos mujeres (1842-1843) se manifiesta contraria a la indisolubilidad del matrimonio; pondrá en tela de juicio las convenciones sociales, figurando dicho lazo como el vínculo que mantiene apresados a los individuos cuando el sentimiento amoroso ha desaparecido (Ayala, 1998). 
Interesantísima resulta la comedia titulada La Aventurera, estrenada con aplauso en la primavera de 1853 (Cotarelo, 1929: 531-535); la autora desvela que se trata de una imitación libre de L'Aventurière (1848), original del escritor francés Emilio Augier, si bien la crítica contemporánea señaló las divergencias existentes entre las dos piezas en cuanto a los caracteres, las situaciones, el desenlace, el género al que pertenecen y el pensamiento moral que desarrollan (Romero Ortiz, 1871: 311-317). Es posible que la Avellaneda al componerla tuviera también presente La dama de las camelias de Alejandro Dumas (hijo), publicada primero como novela en 1848 y cuya versión teatral se llevó a los escenarios parisinos en 1852 (Calvet, 1991: 563).

En La Aventurera se dramatiza un espinoso asunto como es la rehabilitación de la mujer caída. La protagonista, Natalia, está a punto de casarse con un sesentón, Julián; en este enlace no hay motivación económica puesto que ella goza de cuantiosos caudales que guarda depositados en el Banco de Inglaterra. Sólo aspira con este matrimonio a ingresar en sociedad, a lograr una situación que nunca ha conocido:

La de verme en el mundo

con rango de noble esposa;

la de ocupar puesto digno

entre las hembras de honra. (176)

Devorada por amargos recuerdos le confiesa a Julián su sórdido pasado. Nacida en pobre cuna, huérfana y sin nadie que la protegiese, tan sólo se encontró con un monstruo, que fingiéndose su hermano, la convirtió en una cortesana. Su prometido, que aprecia en ella un elevado carácter, está decidido a casarse, saltando por encima de «las necias leyes sociales» (194) que la repudian sin remedio. Pero si Julián ha sentido piedad por la desventurada, por la magdalena arrepentida, sus hijos manifiestan una actitud adversa. La autora, en una magistral escena (II, VIII), enfrenta la postura de Luisa, una joven de 19 años, a la que la fortuna ha sonreído desde su infancia, que ha vivido custodiada por su familia conservando intacta su virtud, con la de la protagonista, que se ha visto abocada a vender su honor a cambio de pan. La intención de la dramaturga es poner de relieve la mísera y desesperante condición de esas criaturas abandonadas para las cuales sólo hay dos caminos: el de la prostitución o el de la indigencia (Romero Ortiz, 1871: 316). Pero Luisa, lejos de compadecerse de la víctima, condena con suma rigidez la conducta de Natalia y lejos de perdonarla, la humilla.

El hijo, Eduardo, es un calavera que ha llevado una vida licenciosa y ha derrochado toda la herencia de su difunta madre. Es la personificación del hombre que invoca la virtud después de haberla escarnecido. Si al principio 
rechaza a Natalia porque una mujer de su reputación no puede sustituir a una dama como era su madre, posteriormente cambia cuando la protagonista, decidida a entrar en un convento, le ofrece todo su dinero para que lo distribuya entre las jóvenes huérfanas a fin de que con esas pequeñas dotes eviten los peligros que a ella le acecharon y se puedan convertir en dignas esposas. Es en ese momento cuando la comedia alcanza todo su sentido, cómo a través de los versos de Eduardo la autora lanza todo un alegato feminista (Bravo Villasante, 1986: 142), señalando la injusticia del código moral de la sociedad española:

Hoy su juicio me ha mostrado

el cielo, por mi conciencia, que me hace claro entender que es enorme sinrazón que la ley de expiación sólo alcance a la mujer; y que el hombre, juez severo de faltas de que es autor, blasone de seductor y después de justiciero. (228)

Por último, nos detendremos en El millonario y la maleta una pieza cómica en dos actos que la autora concibió para ser representada por un teatrillo de aficionados de Sevilla, ciudad donde residió desde 1865 a 1869. Al parecer no llegó a estrenarse y permaneció inédita hasta 1870, en que la incluyó en el tomo III de sus Obras (Cotarelo, 1930: 51).

Se trata de un juguete escénico escrito con habilidad y gracia en el que la dramaturga acude a la deformación caricaturesca de los personajes a fin de procurar la hilaridad de los espectadores/ lectores. Se nos presenta a Doña Policarpa preocupada hasta la obsesión por casar a sus tres hijas en un momento en que según ella «los maridos escasean más que los sastres de conciencia» (Gómez de Avellaneda, 1981: 43). La comicidad se implementa con la salida de la primogénita, Mónica, que está trazada con los rasgos de la bachillera pedante, hablando siempre con frases en latín -vengan o no a cuento- o utilizando palabras altisonantes para referirse a objetos cotidianos. Para Marina Mayoral, la Avellaneda se sirve de los tópicos habituales para ridiculizar el deseo de saber de las mujeres. Para esta crítica, en una época en que éstas empezaban a incorporarse a la cultura y en la que las reivindicaciones feministas pedían la igualdad de instrucción, esta burla de una joven enfadosa por su mala asimilada erudición puede querer decir que ese no es el modelo de mujer sabia que la escritora defiende (Mayoral, 1995: 144-5).

La segunda de las hijas, Rosa, es una coqueta, una cursi que se adorna con tal exageración y mal gusto que Emilio comenta: «Es un jardín ambulante» 
(50). Es el ejemplo de la mujer fatua, sólo pendiente de la moda y de los lujos; su deseo es vivir en la Corte y «tener coche...palcos en los teatros... aderezos de brillantes...vestidos de moaré...» (50). Es la pequeña, Gabriela, la que más se aproxima al tipo de mujer que prefiere la escritora. Indignada porque su madre les trata como si fueran mercancía, con su buen juicio le recrimina: «¿No está cansada todavía de sacarnos al mercado?» (46).

Otro elemento que produce comicidad lo encontramos en el equívoco y en las situaciones que genera (Mayoral, 1995: 146). Debido a las idénticas iniciales de la maleta, los lugareños confunden a Emilio Coello, amante de Gabriela, que ha venido al pueblo para pintar un cuadro destinado al retablo de la iglesia, con un millonario originario de la villa, Esteban Cañizares. Ante el artista desfilan una serie de personajes de lo más pintoresco que lo único que pretenden es conseguir sustanciosas donaciones. Cuando llega el verdadero millonario decidido a descansar de la ajetreada vida de la Corte tiene que soportar con desesperación cómo los pedigüeños vuelven para reclamar las dádivas prometidas por el artista. Con resignación accede a todas las peticiones, a excepción de la de Doña Policarpa, que insiste en enlazarle con su hija Gabriela. El millonario -que ya está casado- propone que la joven se una al hombre que ama, Emilio, cuyo talento le augura un brillante porvenir y para facilitarlo les concede como regalo de bodas su casa natal, que acaba de adquirir.

En suma, este repaso a las comedias de Gertrudis Gómez de Avellaneda nos ha permitido descubrir la voz de una dramaturga valiente, inconformista, que expone abiertamente sus ideas en torno a una serie de problemas que le preocupan, así se manifiesta a favor del amor sin presiones familiares, económicas o sociales, donde se pueda elegir con libertad al cónyuge, rechazando los matrimonios concertados porque sólo traen la infelicidad de los contrayentes. Respecto al papel de la mujer en la sociedad de su tiempo, se atreve a censurar la total dependencia de éstas respecto a los varones en todos los órdenes de la vida, critica cómo están sometidas a unos estrictos códigos de conducta que ellos les imponen, adelantándose en muchos años a las denuncias de las feministas.

\section{BIBLIOGRAFÍA}

AyalA, Máá., «Dos mujeres, novela reivindicativa de Gertrudis Gómez de Avellaneda», Actas del XII Congreso de la Asociación Internacional de Hispanistas, The University of Birmingan, 1998, IV, pp. 76-83.

Bravo Villasante, C., Una vida romántica: la Avellaneda, Madid, Instituto de Cooperación Iberoamericana, 1986. 
CALVET, R. M ${ }^{\mathrm{a}}$, «Las versiones españolas del teatro de Émile Augier», Traducción y Adaptación Cultural: España-Francia, Mª L. Donaire y F. Lafarga (eds.), Universidad de Oviedo, pp. 561-577.

Cotarelo y Mori, E., «La Avellaneda y sus obras», Boletín de la Real Academia Española, 1928, XV, pp. 583-635; 1929, XVI, pp. 5-48; 131-184; 267-325; 395-437; 529-593; 1930, XVII, pp. 5-71; 145-205.

CRUz de Fuentes, L. (ed.), Autobiografía y cartas (hasta ahora inéditas) de la ilustre poetisa Gertrudis Gómez de Avellaneda, Madrid, Imprenta Helénica, 1914, $2^{\mathrm{a}} \mathrm{ed}$.

GIES, D., El Teatro en la España del siglo XIX, Cambrigde University Press, 1996, pp. 271-285.

Gómez de Avellaneda, G., Cartas, en Obras de..., 1974, Edición y estudio preliminar de J. Ma Castro y Calvo, Madrid, Atlas, I.

- Errores del corazón y otras comedias, selección, prólogo y notas de M. Cruz, La Habana, Editorial Arte y Literatura, 1977, pp. 40-124.

- Simpatía y antipatía, en Errores del corazón y otras comedias, selección, prólogo y notas de M. Cruz, La Habana, Editorial Arte y Literatura, 1977, pp. 359-426.

- La hija de las flores o Todos están locos, en Obras de..., Edición y estudio preliminar de J. Ma Castro y Calvo, Madrid, Atlas, 1979, III, pp. 93-162.

- La Aventurera, en Obras de..., edición y estudio preliminar de J. M ${ }^{a}$ Castro y Calvo, Madrid, Atlas, 1979, III, pp. 163-228.

- Oráculos de Talía o Los duendes en palacio, en Obras de..., edición y estudio preliminar de J. Ma Castro y Calvo, Madrid, Atlas 1979, III, pp. 229- 321.

- El millonario y la maleta, en Obras de..., edición y estudio preliminar de J. Ma Castro y Calvo, Madrid, Atlas, 1981, IV, pp. 41-67.

- Tres amores, en Obras de..., edición y estudio preliminar de J. M $\mathrm{M}^{\mathrm{a}}$ Castro y Calvo, Madrid, Atlas, 1981, IV, pp. 127- 167.

Mayoral, M., «Lo cómico en la obra de G. G. de Avellaneda», Romanticismo 5, Roma Bulzoni, 1995, pp. 143-151.

Romero Ortiz, A., «Juicio crítico del drama La Aventurera», publicado en La Nación el 7 de junio de 1853, recogido en Obras literarias de la Señora Doña Gertrudis Gómez de Avellaneda. Colección Completa. Madrid, Imprenta y Estereotipia de M. Rivadeneyra, V, 1871, Apéndice, pp. 311-317.

Rubio JimÉnEZ, J., El teatro en el siglo XIX (II) (1845-1900), en Historia del teatro en España, dirig. por J. Mª Díez Borque, Madrid, Taurus, 1988, II.

VillaVerde, L., «Gertrudis Gómez de Avellaneda, dramaturga ecléctica», Homenaje a Gertrudis Gómez de Avellaneda. Memorias del simposio en el centenario de su muerte, ed. a cargo de G. Zaldívar y R. Martínez de Cabrera, Miami, Ediciones Universal, 1981, pp. 200-209. 